\title{
Granulometric Characterization of Wood Dust Emission from CNC Machining of Natural Wood and Medium Density Fiberboard
}

\author{
Richard Kminiak ${ }^{1}$, Martin Kučerka ${ }^{2} \mathbb{D}$, Lubos Kristak ${ }^{1, * \mathbb{D}}$, Roman Reh ${ }^{1}$, Petar Antov ${ }^{3, * \mathbb{D}}$, Alena Očkajová ${ }^{2} \mathbb{D}$, \\ Tomasz Rogoziński 4 (i) and Marta Pędzik 4,5 (D) \\ 1 Faculty of Wood Sciences and Technology, Technical University in Zvolen, 96001 Zvolen, Slovakia; \\ xkminiak@tuzvo.sk (R.K.); roman.reh@tuzvo.sk (R.R.) \\ 2 Faculty of Natural Sciences, Matej Bel University, 97401 Banská Bystrica, Slovakia; \\ martin.kucerka@umb.sk (M.K.); alena.ockajova@umb.sk (A.O.) \\ 3 Faculty of Forest Industry, University of Forestry, 1797 Sofia, Bulgaria \\ 4 Faculty of Forestry and Wood Technology, Poznan University of Life Sciences, 60-627 Poznan, Poland; \\ tomasz.rogozinski@up.poznan.pl (T.R.); marta.pedzik@itd.lukasiewicz.gov.pl (M.P.) \\ 5 Łukasiewicz Research Network, Wood Technology Institute, 60-654 Poznan, Poland \\ * Correspondence: kristak@tuzvo.sk (L.K.); p.antov@ltu.bg (P.A.)
}

\section{check for} updates

Citation: Kminiak, R.; Kučerka, M.; Kristak, L.; Reh, R.; Antov, P.; Očkajová, A.; Rogoziński, T.; Pędzik, M. Granulometric Characterization of Wood Dust Emission from CNC Machining of Natural Wood and Medium Density Fiberboard. Forests 2021, 12, 1039. https://doi.org/ 10.3390/f12081039

Academic Editors: Michele Brunetti and Michela Nocetti

Received: 20 May 2021

Accepted: 3 August 2021

Published: 5 August 2021

Publisher's Note: MDPI stays neutral with regard to jurisdictional claims in published maps and institutional affiliations.

Copyright: (c) 2021 by the authors. Licensee MDPI, Basel, Switzerland. This article is an open access article distributed under the terms and conditions of the Creative Commons Attribution (CC BY) license (https:// creativecommons.org/licenses/by/ $4.0 /)$.
Abstract: The aim of this paper was to determine the particle size composition of wood dust emission from CNC milling of natural wood and medium-density fiberboard (MDF) and evaluate the associated occupational exposure risks. The paper is focused on some of the most commonly used materials in the woodworking and furniture industry, i.e., solid wood (beech, oak, and spruce) and composite materials (MDF panels). In addition to the influence of the machined material, the effect of the technical-technological parameters, namely, feed speed and depth of cut on the particle size distribution, was also investigated. The selected values of the technical-technological parameters used in this study followed the common work practice in small wood processing companies. The particle size distribution was evaluated by using sieve analysis of samples from the total mass of collected wood dust. The results demonstrated that machining of natural wood is characterized mostly by the formation of coarse dust fractions ( $2 \mathrm{~mm}-1 \mathrm{~mm}$ sieves), whilst the processing of MDF was associated with generation of fine dust fractions with a size below $100 \mu \mathrm{m}$. The results obtained can be used for optimizing the technological programs of $\mathrm{CNC}$ milling machines, thus, reducing the occupational exposure to harmful wood dust emissions in the wood-processing industry.

Keywords: occupational health; wood-based composites; medium density fiberboard; wood dust; particle size distribution; CNC machining

\section{Introduction}

The workability of natural wood and wood-based materials is almost always associated with the formation of different fractions of particles that disperse in the air and inside the production premises, posing serious occupational health risks for workers [1-5]. By-products from woodworking processes, such as sawdust and wood dust, can have adverse effects on human health if they are not sufficiently controlled and effectively aspirated by dust extraction systems [6-9]. Computerized numerical control (CNC) machines appear to be problematic devices from the point of view of dust extraction equipment and suction of the smallest wood particles, as the particle remains in the working space of the CNC machine. Wood and wood-based material processing plants with improved working conditions can increase the precision of production or the reliability of finished products, thus, strengthening their position on the market [10]. Large companies do not have a problem with the transition to modern CNC technology, but in the case of small ones, it is, 
in many cases, complicated. It creates many technical and technological problems for them, and increased dust in the workplace is one of them [11-15].

A significant proportion of the accumulated wood particles that are not displaced by suction represent a health hazard for workers [16]. The particles lose momentum after hitting the edge of the suction basket and fall on the workpiece, on the clamping beams, or into the so-called collecting trough under the workpiece. The usual practice of the operator is to clean (blow) the surface of the furniture blank, as well as the clamping beams, using compressed air after the completion of all technological operations [17]. The worker, thus, sends the accumulated particles airborne (especially the fine dust fractions) not only in the working space of the CNC machine but also in the space of the entire workshop. Thus, the operator is directly exposed to fine dust particles, and also, dust dispersed in the air may constitute a fire and explosion hazard, which poses an immediate health risk $[18,19]$.

Occupational exposure to wood dust can cause significant non-reversible human health problems, including skin, eye, and nose irritation [20]; asthma [21]; skin disorders (dermatitis) [22]; and adverse respiratory system effects, including decreased lung capacity, chronic obstructive pulmonary disease, and allergic reactions $[23,24]$, as well as toxic effects specific to some wood species. Markedly, wood dust has been classified as carcinogenic to humans (Group 1) by the International Agency for Research on Cancer (IARC) [25]. According to IARC, wood dust causes cancers of the nasal cavity, paranasal sinuses, and nasopharynx, which have been observed mostly among workers exposed to hardwood dust. The recent European Union (EU) directives also classified hardwood dust as carcinogenic to humans and set an occupational exposure limit (OEL) of $2 \mathrm{mg} \cdot \mathrm{m}^{-3}$ of inhalable hardwood dust fraction calculated or measured for a reference 8 -h period with a transitional limit value of $3 \mathrm{mg} \cdot \mathrm{m}^{-3}$ until January 2023 [26]. In addition, in 2002, the Scientific Committee for Occupational Exposure Limits (SCOEL) of the EU stated that wood dust exposure higher than $0.5 \mathrm{mg} \cdot \mathrm{m}^{-3}$ can cause pulmonary effects and, thus, should be avoided [27]. It is more likely for people whose occupations are associated with wood dust exposure to develop various diseases associated with respiratory problems, including lung cancer. The risk of lung cancer has increased in those who have been exposed to wood dust for more than 10 years and have taken more than 40 years of occupation since the first exposure [28]. In addition, wood dust is considered to be one of the ten most common causes of occupational asthma. Dust toxicity depends largely on the type of wood raw material and products based on lignocellulosic raw materials, which results from the different content of chemical components and the hardness of the raw material [29].

The extent of harmful effects of wood dust to humans depends on many factors, such as the characteristics and size of dust particles, their concentration in the air, the duration and conditions of their action, and the sensitivity of each individual to the dust particles. In general, these dust fraction characteristics depend on the processing technology and machinery used, machining parameters, and type of processed wood material. Several studies reported very similar particle size distributions between pine and oak; others reported that hardwood dust is finer than softwood dust [25]. Depending on the treatments to which wood has been subjected before machining, dust can contain preservatives, additives, or adhesives [30-38]. The greatest occupational risk is caused by the finest dust particles (inhalable fraction), which, when dispersed in the ambient air, can lead to serious short-term and long-term human health problems $[39,40]$. Therefore, in order to select and implement the necessary preventive measures, it is essential to know the characteristics of the machined natural wood and wood-based materials, as well as their properties [41-44].

Since problems associated with exposure to wood dust were confirmed by many epidemiologic studies, producers have made great efforts to minimize it. There are three basic ways to reduce the hazards arising from occupational exposure to wood dust, namely, the selection and application of proper technological parameters of processing to minimize the creation of the most dangerous dust fractions; use of dust control and dust extraction and filtration systems, and/or use of proper respiratory protective equipment, such as face masks [45-49]. 
The aim of this paper was to analyze the particle size composition of wood dust emission from CNC milling of natural wood and medium-density fiberboard (MDF) and evaluate the associated occupational exposure risks to the health and safety of employees in the wood-processing industry.

\section{Materials and Methods}

\subsection{CNC Machine}

The experiments were carried out on a 5-axis CNC machining center SCM Tech Z5 manufactured by the company SCM Group, Headquarters Via Emilia 77, 47,921 Rimini $(\mathrm{RN})$, Italy. The basic technical parameters of the machining center given by the manufacturer are provided in Table 1.

Table 1. Technical and technological parameters of CNC Machining Centre SCM Tech Z5 used in this work.

\begin{tabular}{|c|c|}
\hline Useful desktop & $x=3050 \mathrm{~mm}, y=1300 \mathrm{~mm}, \mathrm{z}=300 \mathrm{~mm}$ \\
\hline Speed $X$ axis & $0 \div 70 \mathrm{~m} \cdot \mathrm{min}^{-1}$ \\
\hline Speed $Y$ axis & $0 \div 40 \mathrm{~m} \cdot \mathrm{min}^{-1}$ \\
\hline Speed $Z$ axis & $0 \div 15 \mathrm{~m} \cdot \mathrm{min}^{-1}$ \\
\hline Vector rate & $0 \div 83 \mathrm{~m} \cdot \mathrm{min}^{-1}$ \\
\hline \multicolumn{2}{|c|}{$\begin{array}{l}\text { Parameters of the Main Spindle } \\
\text { Electric Spindle with HSK F63 Connection }\end{array}$} \\
\hline Rotation axis $\mathrm{C}$ & $640^{\circ}$ \\
\hline Rotation axis B & $320^{\circ}$ \\
\hline Revolutions & $600 \div 24,000 \mathrm{rpm}$ \\
\hline \multirow{2}{*}{ Power } & 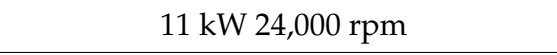 \\
\hline & $7.5 \mathrm{~kW} \mathrm{10,000} \mathrm{rpm}$ \\
\hline \multirow{2}{*}{ Maximum tool diameter } & $\mathrm{D}=160 \mathrm{~mm}$ \\
\hline & $\mathrm{L}=180 \mathrm{~mm}$ \\
\hline
\end{tabular}

\subsection{Tool Parameters}

The characteristics of the tool used were as follows: a shank cutter with one reversible cutting insert with the designation KARNED 4451, manufactured by Karned Tools, s.r.o., Praha, Czech Republic (Figure 1), was used in this experiment. The basic technical and technological parameters given by the manufacturer are provided in Table 2. Reversible cutting inserts HW 49.5/9/1.5 made of the sintered carbide material T10MG were mounted in end mills from the company BOTO, s.r.o., Nové Zámky, Slovakia. The basic technical parameters of the sintered carbide material given by the manufacturer are provided in Table 3.
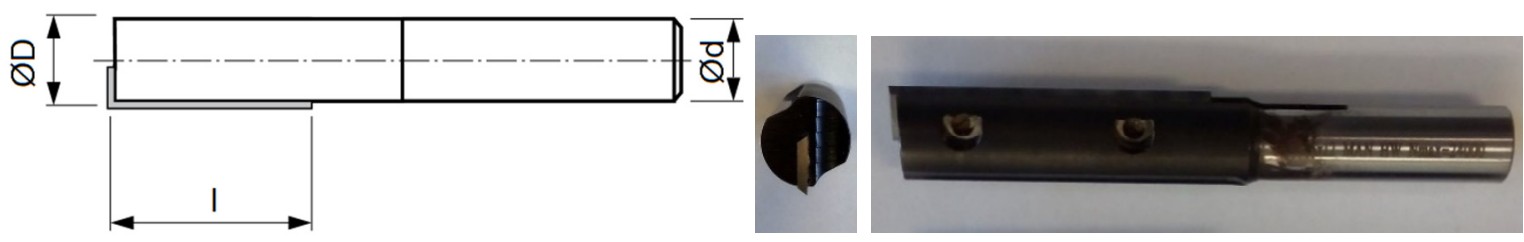

Figure 1. End mill used in the experiment-KARNED 4451 (ØD—working average, l-working length, Ødclamping diameter). 
Table 2. Technical and technological parameters of the milling cutter.

\begin{tabular}{cccccc}
\hline Miller & $\begin{array}{c}\text { Working } \\
\text { Diameter D [mm] }\end{array}$ & $\begin{array}{c}\text { Working Length } \\
\mathbf{1}[\mathbf{m m}]\end{array}$ & $\begin{array}{c}\text { Diameter of the } \\
\text { Chucking Shank } \\
\mathbf{d}[\mathbf{m m}]\end{array}$ & $\begin{array}{c}\text { Dimensions of } \\
\text { Used Blades } \\
\mathbf{L} \times \mathbf{W} \times \mathbf{T}[\mathbf{m m}]\end{array}$ & $\begin{array}{c}\text { Blade Material } \\
\text { KARNED 4451 }\end{array}$ \\
\hline
\end{tabular}

Table 3. Technical parameters of sintered carbide tigra.

\begin{tabular}{|c|c|c|c|c|c|c|c|}
\hline \multirow{2}{*}{$\begin{array}{c}\text { Classes of } \\
\text { TIGRA }\end{array}$} & \multirow{2}{*}{ ISO CODE } & \multirow{2}{*}{ US CODE } & \multirow{2}{*}{ Binder \% } & \multicolumn{2}{|c|}{ Hardness } & \multicolumn{2}{|c|}{ Bending Strength } \\
\hline & & & & HV10 & $\mathrm{HRA} \pm \mathbf{0 . 2}$ & $\mathrm{N} / \mathrm{mm}^{2}$ & Psi \\
\hline T10MG & K10-K40 & $\mathrm{C} 3+$ & 10 & 1650 & 92.3 & 3600 & 522,000 \\
\hline
\end{tabular}

A milling cutter tool with reversible cutting inserts was selected for conducting the experiments because it is a frequently used tool in small woodworking companies due to low operational costs (the tool does not need to be reground; in case of dullness, only reversible cutting inserts will be turned or replaced). In addition, this tool has zero inclination to the main cutting edge (the cutting edge is parallel to the tool axis), and thus, there is mainly axial removal of particles.

The production of furniture blanks was chosen for the purpose of the experiments. Roughly formatted blanks are finished to nominal size by milling on a CNC machining center (created either by sawing on a formatting circular saw or by nesting milling directly on the $\mathrm{CNC}$ machining center) with subsequent technological operations to create technological holes for connectors and fasteners. This represents the so-called finishing technological operation (milling in which the final part is created from the workpiece, where the machining allowances from the side edges of furniture blanks are removed.

This allowance can range from $1 \mathrm{~mm}$ (typical machining allowance) to $5 \mathrm{~mm}$ (limiting thickness of residual material in nesting milling), depending on the type of previous technological operation. An accompanying phenomenon of milling is that a considerable number of particles formed are not sucked out (production variability requires universal suction baskets typical of their large dimensions and axial outlet for suction pipes). The particle leaves the tool due to the centrifugal force in the radial direction and the individual particles have considerable kinetic energy and fall on the workpiece, on the clamping beams, or into the so-called collecting trough under the workpiece, and they remain in the working space of the $\mathrm{CNC}$ machine.

\subsection{Workpiece}

Tangential furniture blanks with moisture content $\mathrm{w}=8 \% \pm 1 \%$ from two commonly used hardwood species, i.e., common beech (Fagus sylvatica L.) and sessile oak (Quercus petraea (Matt.) Liebl.), and one softwood species, Norway spruce (Picea abies L.), were used to conduct the experiments. Wood samples were obtained from the School Forest Enterprise (ŠLP) Lieskovec of the Technical University in Zvolen and machined along the material.

The dimensions of the furniture blanks used were as follows: thickness $\mathrm{h}=20 \pm 0.25 \mathrm{~mm}$, width $\breve{s}=80 \pm 0.25 \mathrm{~mm}$ and length $1=500 \pm 1 \mathrm{~mm}$. The blank surfaces were machined by face milling. Each sample blank was manipulated from a different pillar cutout within a given combination of the technical and technological parameters, i.e., feed speed/and depth of cut.

In addition to raw wood, MDF boards were used, popularly used in the production of furniture and interior finishing products. The production of this type of medium and high density wood material accounts for almost $30 \%$ of world production compared to all types of wood-based panels (based on FaoStat data from 2019). Raw MDF panels manufactured by the company Kronospan Polska sp. z o.o., ul. Waryńskiego 1, PL-78-400 Szczecinek, Poland, were used for conducting the experiments. The main technical characteristics of 
the MDF panels used in this work are presented in Table 4. The processed MDF blanks had a thickness $h=20 \mathrm{~mm}$, width $=500 \mathrm{~mm}$, and length $1=500 \mathrm{~mm}$. The density of MDF panels was $750 \mathrm{~kg} \cdot \mathrm{m}^{-3}$.

Table 4. Technical parameters of the raw MDF panels used in this work.

\begin{tabular}{|c|c|c|}
\hline Property & Test Method & Request \\
\hline Thickness tolerance & EN 324-1 [50] & $\pm 0.3 \mathrm{~mm}$ \\
\hline Dimensions tolerance & EN 324-1 & $\pm 5.0 \mathrm{~mm}$ \\
\hline Squareness tolerance & EN 324-2 [51] & $\pm 2 \mathrm{~mm} \cdot \mathrm{m}^{-1}$ \\
\hline Humidity & EN 322 [52] & $4 \div 11 \%$ \\
\hline Formaldehyde release & EN ISO 12460-5 [53] & $<8 \mathrm{mg} / 100 \mathrm{~g}$ a. s. samples \\
\hline Thickness range & & $\begin{array}{c}6-9 ; 9-12 ; 12-19 ; 19-30 ; 30-45 \\
(\mathrm{~mm})\end{array}$ \\
\hline Bending strength (modulus of rupture) & EN 310 [54] & $\begin{array}{c}23 ; 22 ; 20 ; 18 ; 17 \\
(\mathrm{MPa})\end{array}$ \\
\hline Tensile strength & EN 319 [55] & $\begin{array}{c}0.65 ; 0.60 ; 0.55 ; 0.55 ; 0.50 \\
(\mathrm{MPa})\end{array}$ \\
\hline Thickness swelling (24h) & EN 317 [56] & $17 ; 15 ; 12 ; 10 ; 8 ;(\%)$ \\
\hline Modulus of elasticity & EN 310 & $\begin{array}{c}2800 ; 2500 ; 2200 ; 2150 ; 1900 \\
(\mathrm{MPa})\end{array}$ \\
\hline
\end{tabular}

\subsection{Milling Parameters}

The workpiece was milled with an end mill under the following conditions: depth of cut $\mathrm{e}=1,3$, and $5 \mathrm{~mm}$; cutter speed $\mathrm{n}=20,000 \mathrm{~min}^{-1}$; feed speed $\mathrm{vf}=1,3$, and $5 \mathrm{~m} \mathrm{~min}^{-1}$. For each combination of parameters, six samples were milled.

Samples for particle size analysis of wood dust were taken isokinetically from the exhaust pipe of the CNC woodworking center in accordance with the STN ISO 9096:202102 (83 4610) standard [57]. The particle size distribution was determined by sieving. A special set of stacked sieves was used for this purpose $(2 \mathrm{~mm}, 1 \mathrm{~mm}, 0.5 \mathrm{~mm}, 0.25 \mathrm{~mm}$, $0.125 \mathrm{~mm}, 0.063 \mathrm{~mm}, 0.032 \mathrm{~mm}$, and bottom) placed on the vibrating stand of the screening machine Retsch AS 200c (Retsh GmbH, Haan, Germany). The sieving parameters were in accordance with ISO 3310-1 [58]: sieve interruption frequency $20 \mathrm{~s}$, network deflection amplitude $2 \mathrm{~mm} \cdot \mathrm{g}^{-1}$, screening time $\tau=15 \mathrm{~min}$, weight $50 \mathrm{~g}$. The particle size distribution was obtained by weighing the proportions remaining on the sieves after sieving on an electric laboratory balance Radwag 510/C / 2 (Radwag Balances and Scales, Radom, Poland) with weighing accuracy $0.001 \mathrm{~g}$. Screening was performed on three samples for each combination of parameters.

Multi-factor statistical analysis of variance (ANOVA) was carried out to discern significant difference at 95\% level of confidence, using specialized SAS software program (version 9.2, Cary, NC, USA).

\section{Results and Discussion}

It is possible to sort out the investigated materials into two groups from the point of view of the obtained results of the composition of the majority of the particles into particle grain size level. The first level consists of natural wood, in which we can characterize most of the particles as an area with a tendency to roll in the direction of particle separation. The second level consists of composite material MDF, of which the majority is formed by the dust particles, on the other hand.

In the case of natural wood, the majority share was formed by the so-called coarse fractions (fractions collected on the $2 \mathrm{~mm}$ and $1 \mathrm{~mm}$ sieve), followed by the medium-coarse fractions (collected on the sieves $500 \mu \mathrm{m}$ and $250 \mu \mathrm{m}$ ), and the smallest percentage had the so-called fine fractions (collected on a $125 \mu \mathrm{m}$ sieve, $63 \mu \mathrm{m}, 32 \mu \mathrm{m}$, and bottom). In the 
case of MDF panels, the results were reversed, i.e., the coarse and medium-coarse fractions were almost negligible, and the largest amount of wood particles was found among the fine dust fractions, as seen in Table 5.

Table 5. Average particle size distribution according to individual combinations of monitored parameters: depth of cut, e, feed speed, vf.

\begin{tabular}{|c|c|c|c|c|c|c|c|c|c|c|}
\hline \multirow{3}{*}{$\begin{array}{l}\text { Sieve Mesh } \\
{[\mathrm{mm}]}\end{array}$} & \multirow{3}{*}{ Fraction Type } & \multicolumn{9}{|c|}{ Beech, Thickness 22 mm, Cutting Insert } \\
\hline & & I. & II. & III. & IV. & V. & VI. & VII. & VIII. & IX. \\
\hline & & vf1-e/1 & vf3-e/1 & vf5-e/1 & vf1-e/3 & vf3-e/3 & vf5-e/3 & vf1-e/5 & vf3-e/5 & vf5-e/5 \\
\hline $\begin{array}{l}2.000 \\
1.000\end{array}$ & coarse & 94.2 & 96.86 & 95.36 & 90.58 & 75.5 & 66.85 & 67.22 & 47.24 & 46.94 \\
\hline $\begin{array}{l}0.500 \\
0.250\end{array}$ & $\begin{array}{l}\text { medium } \\
\text { coarse }\end{array}$ & 3.09 & 2.03 & 3.68 & 5.95 & 19.09 & 29.49 & 21.27 & 36.69 & 47.38 \\
\hline $\begin{array}{c}0.125 \\
0.063 \\
0.032 \\
<0.032\end{array}$ & fine & 2.68 & 1.12 & 0.95 & 3.46 & 5.41 & 3.67 & 11.51 & 16.07 & 5.67 \\
\hline & & & & & k, thickn & ss $22 \mathrm{~mm}$ & utting in & & & \\
\hline $\begin{array}{l}\text { Sieve mesh } \\
{[\mathrm{mm}]}\end{array}$ & Fraction type & I. & II. & III. & IV. & V. & VI. & VII. & VIII. & IX. \\
\hline & & vf1-e/1 & vf3-e/1 & vf5-e/1 & vf1-e/3 & vf3-e/3 & vf5-e/3 & vf1-e/5 & vf3-e/5 & vf5-e/5 \\
\hline $\begin{array}{l}2.000 \\
1.000 \\
\end{array}$ & coarse & 90.56 & 82.71 & 81.89 & 74.85 & 80.72 & 64.19 & 58.91 & 50.96 & 55.51 \\
\hline $\begin{array}{l}0.500 \\
0.250\end{array}$ & $\begin{array}{l}\text { medium } \\
\text { coarse }\end{array}$ & 3.86 & 11.91 & 13.56 & 17.85 & 13.53 & 30.47 & 26.06 & 35.37 & 38.9 \\
\hline $\begin{array}{c}0.125 \\
0.063 \\
0.032 \\
<0.032\end{array}$ & fine & 5.57 & 5.38 & 4.56 & 7.3 & 5.75 & 5.34 & 15.03 & 13.66 & 5.59 \\
\hline & & & & $\mathrm{Sp}_{1}$ & ce, thick & ess $22 \mathrm{~m}$ & cutting $\mathrm{i}$ & sert & & \\
\hline $\begin{array}{c}\text { Sieve mesh } \\
\text { [mm] }\end{array}$ & Fraction type & I. & II. & III. & IV. & V. & VI. & VII. & VIII. & IX. \\
\hline & & vf1-e/1 & vf3-e/1 & vf5-e/1 & vf1-e/3 & vf3-e/3 & vf5-e/3 & vf1-e/5 & vf3-e/5 & vf5-e/5 \\
\hline $\begin{array}{l}2.000 \\
1.000 \\
\end{array}$ & coarse & 64.12 & 73.4 & 65.1 & 67.3 & 57.1 & 59.69 & 65.16 & 52.04 & 63.33 \\
\hline $\begin{array}{l}0.500 \\
0.250\end{array}$ & $\begin{array}{l}\text { medium } \\
\text { coarse }\end{array}$ & 24.48 & 18.39 & 25.34 & 21.16 & 32.23 & 33.23 & 22.17 & 37.54 & 31.2 \\
\hline $\begin{array}{c}0.125 \\
0.063 \\
0.032 \\
<0.032\end{array}$ & fine & 11.39 & 8.22 & 9.56 & 11.54 & 10.68 & 7.09 & 12.67 & 10.42 & 5.47 \\
\hline & & & & & F, thickn & ss $22 \mathrm{~mm}$ & cutting ir & & & \\
\hline $\begin{array}{c}\text { Sieve Mesh } \\
\text { [mm] }\end{array}$ & Fraction type & I. & II. & III. & IV. & V. & VI. & VII. & VIII. & IX. \\
\hline & & vf1-e/1 & vf3-e/1 & vf5-e/1 & vf1-e/3 & vf3-e/3 & vf5-e/3 & vf1-e/5 & vf3-e/5 & vf5-e/5 \\
\hline $\begin{array}{l}2.000 \\
1.000 \\
\end{array}$ & coarse & 0.51 & 0.36 & 0.32 & 0.43 & 0.38 & 0.27 & 0.31 & 0.32 & 0.28 \\
\hline $\begin{array}{l}0.500 \\
0.250 \\
\end{array}$ & $\begin{array}{l}\text { medium } \\
\text { coarse }\end{array}$ & 1.14 & 1.8 & 2.82 & 1.63 & 1.8 & 5.62 & 0.96 & 2.86 & 9.61 \\
\hline $\begin{array}{c}0.125 \\
0.063 \\
0.032 \\
<0.032\end{array}$ & fine & 98.35 & 97.83 & 96.87 & 97.94 & 97.82 & 94.11 & 98.71 & 96.82 & 90.1 \\
\hline
\end{tabular}


From the point of view of the weight share of coarse fractions, their total weight representation was comparable in the case of beech and oak, beech $(46.94 \% \div 96.86 \%)$ and oak $(50.96 \div 90.56 \%)$, whereas a large part was formed by particles over $2 \mathrm{~mm}$. In the case of softwood material (spruce), the coarse fraction represented a smaller proportion $(52.04 \% \div 73.4 \%$ ), and the fraction ratio above $2 \mathrm{~mm}$ and below $2 \mathrm{~mm}$ was balanced. Graphical representation of the coarse dust fractions is presented in Figures 2 and 3. Coarse fractions consisted of particles called leaf (length and width exceeded the particle thickness several times). This corresponds to the intensity of differences in the structure of early and late wood, which grows in the range of spruce, oak, beech, as well as the individual physical and mechanical properties of wood when the values of spruce vary in other intentions (lower values) than beech and oak. From the point of view of the influence of technical and technological properties, it was not possible to observe a clear influence of the feed rate, although it could be expected that as the feed rate increases, the thickness profile changes (nominal particle thickness increases,) which affects the force ratios in the particle and its disintegration (development corresponds to the given theory within the particle size distribution of beech) [44]. With regard to depth of cut, it is possible to generalize the trend that as the depth of cut increases, the proportion of coarse fractions decreases due to particle elongation with unchanged nominal thickness. This trend was also confirmed by previous studies [59].

Data collected were subjected to multi-factor statistical analysis of variance ANOVA, performed separately for each particle grain size grade. It was determined that during the machining of MDF panels, no particles having the size of $500 \mu \mathrm{m}$ and higher were formed, while in the case of natural wood, there were significantly more of them, as shown in Figures 2-4. We can also define the particles as 'leaf' within the given grain size grades. The initial zone of particle growth is the primary source of the given fractions (milling process is opposite, particle thickness increases from zero to maximum) in terms of particle crushing mechanism, and therefore, within beech and oak particles, it was possible to observe the influence of technical and technological factors. The particles friability increased with increasing the feed rate. Thus, the proportion of the given fractions increased, and it elongated the particle with increasing depth of cut, flattening the thickness profile. However, the statement does not correspond to the course of machining in the case of spruce where the development is ambiguous, which we attribute to the specifics of the material already mentioned.
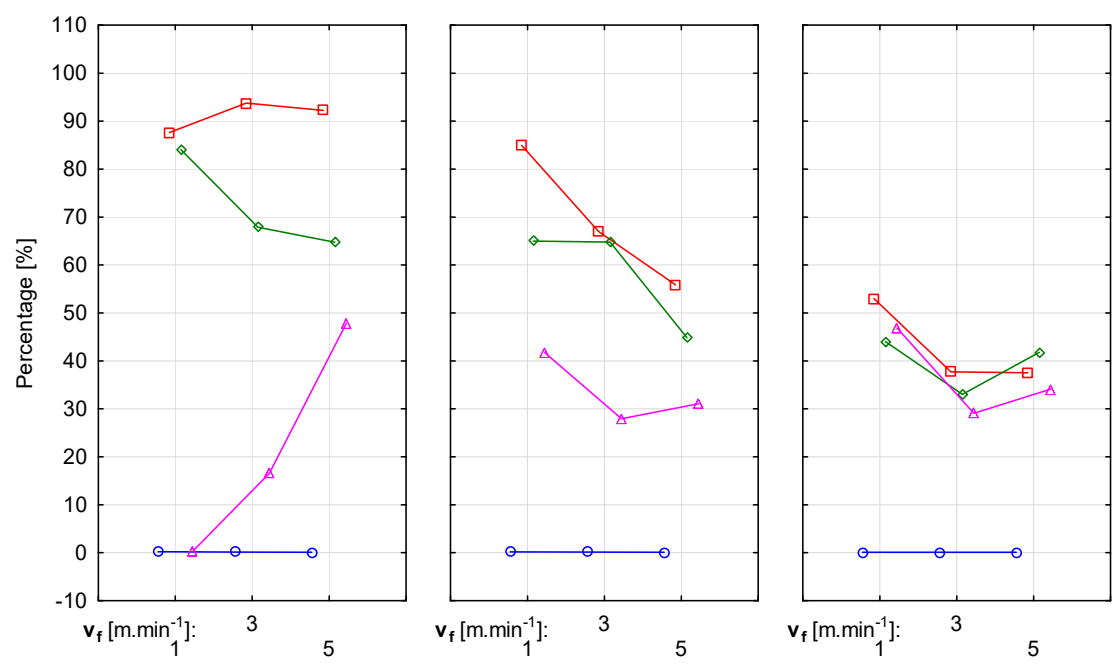

Depth of cut e [mm]: 1

Depth of cut e [mm]: 3

${ }^{*} V_{f}$ - feed speed $\left[\mathrm{m} \cdot \mathrm{min}^{-1}\right]$

Materials: $\Phi$ MDF $\Phi$ Beech $\Phi$ Oak $\#$ Spruce

Figure 2. Grain size grade $2 \mathrm{~mm}$. 


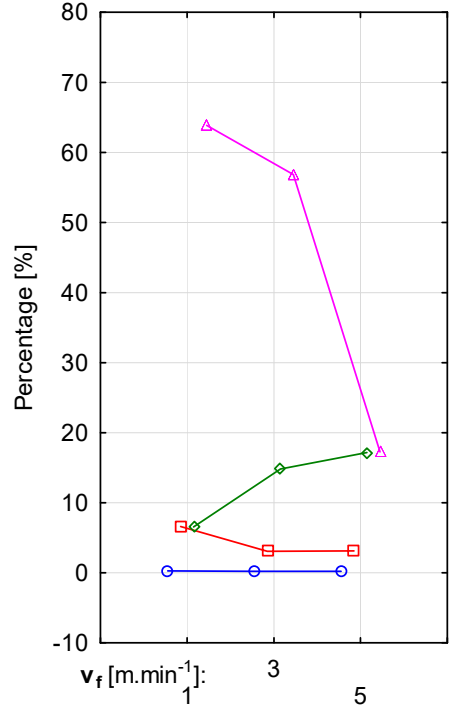

Depth of cut $\mathbf{e}[\mathrm{mm}]: 1$

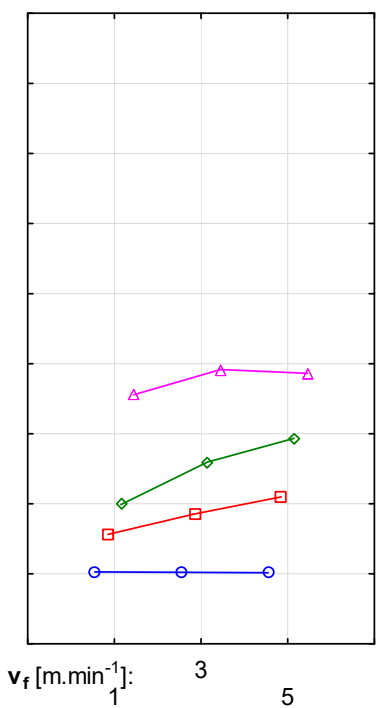

Depth of cut e [mm]: 3

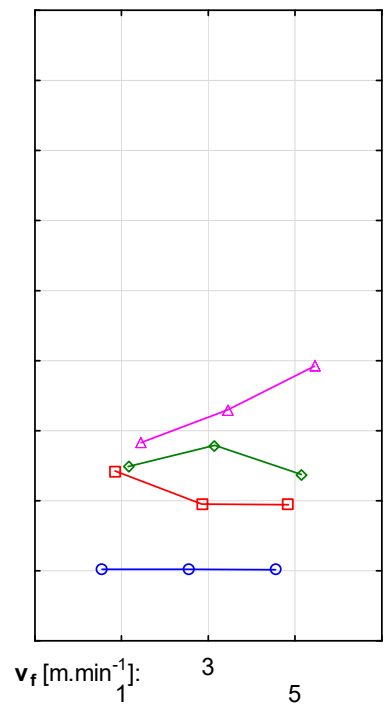

Depth of cut $\mathbf{e}[\mathrm{mm}]: 5$ ${ }^{*} \mathrm{~V}_{\mathrm{f}}$ - feed speed [m.min ${ }^{-1}$ ]

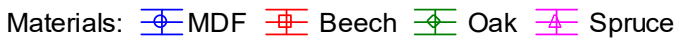

Figure 3. Grain size grade $1 \mathrm{~mm}$.

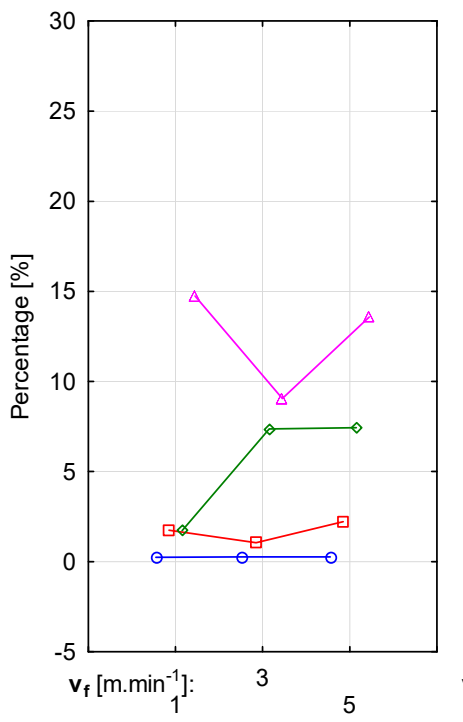

Depth of cut e [mm]: 1

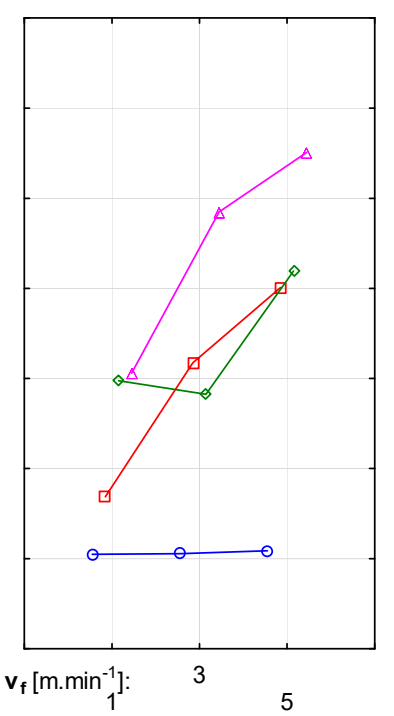

Depth of cut e $[\mathrm{mm}]: 3$

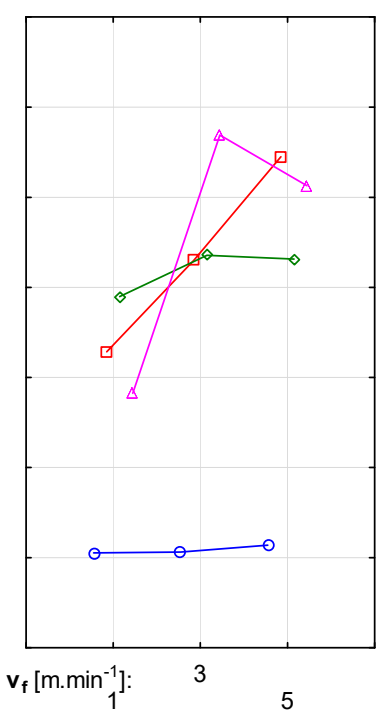

Depth of cut e [mm]: 5 ${ }^{*} v_{f}-$ feed speed $\left[\mathrm{m} \cdot \mathrm{min}^{-1}\right]$

Materials: $\bar{\Phi}$ MDF 车 Beech $\bar{\Phi}$ Oak 포 Spruce

Figure 4. Grain size grade $500 \mu \mathrm{m}$.

Graphical representation of the medium-coarse fraction is presented in Figure 5. It became obvious that in the case of MDF panels, the proportion of the $250 \mu \mathrm{m}$ fraction increased with increasing the depth of cut and feed rate. When processing natural wood, the share of this fraction also increased. 


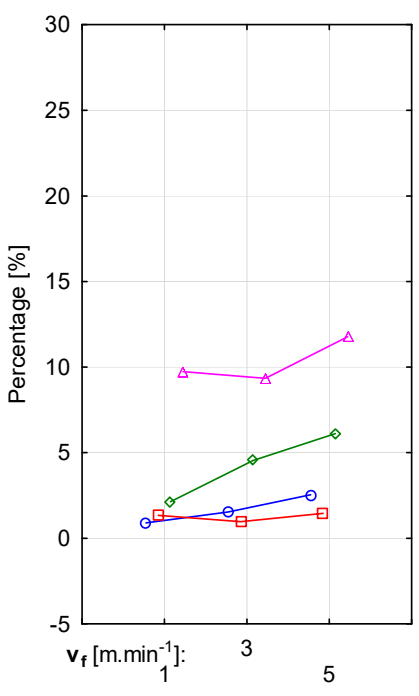

Depth of cut $\mathbf{e}[\mathrm{mm}]: 1$

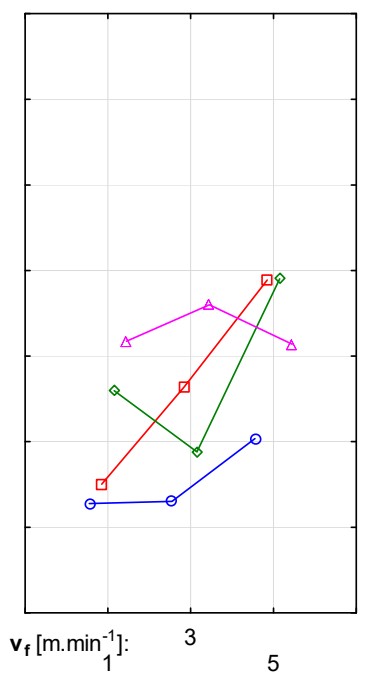

Depth of cut $\mathbf{e}[\mathrm{mm}]: 3$

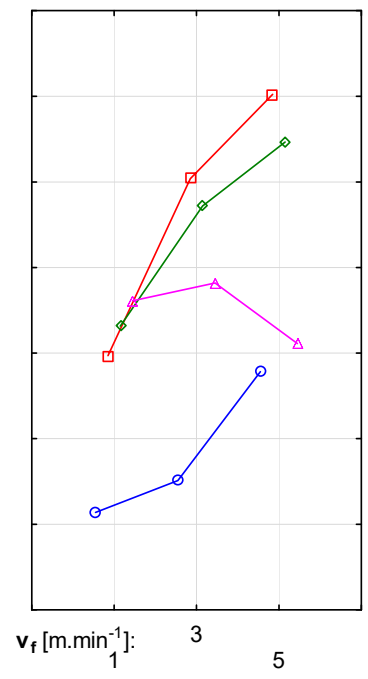

Depth of cut $\mathbf{e}[\mathrm{mm}]: 5$

${ }^{*} v_{f}-$ feed speed $\left[\mathrm{m} \cdot \mathrm{min}^{-1}\right.$ ]

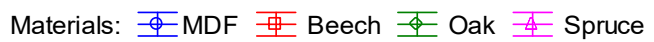

Figure 5. Grain size grade $250 \mu \mathrm{m}$.

Fine fractions, presented in Figures 6-9, are of the greatest importance from the point of view of assessing the occupational health risks to workers. Their distribution in machining natural wood was as follows: $0.95 \% \div 16.07 \%$ (beech), $5.34 \% \div 15.03 \%$ (oak), and $5.47 \% \div 12.67 \%$ (spruce), respectively. Noticeably, no particles from the dust fractions below $32 \mu \mathrm{m}$ were determined. However, the finest dust particles that could be respirable when dispersed in the air are included in the larger sieve fractions. Due to their shape, they cannot pass through sieves with small apertures and join to the larger particles. The weight ratio of particles below $125 \mu \mathrm{m}$ was represented by the following shares: $0.45 \% \div 4.06 \%$ (beech), oak wood $0.92 \% \div 5.86 \%$ (oak), and $1.72 \% \div 5.5 \%$ (spruce), respectively. The onset part of the nominal particle and the intensity of surface destruction in the particle formation process is the primary source of particles classified as fine fractions (a certain indicator of this destruction is the surface roughness).
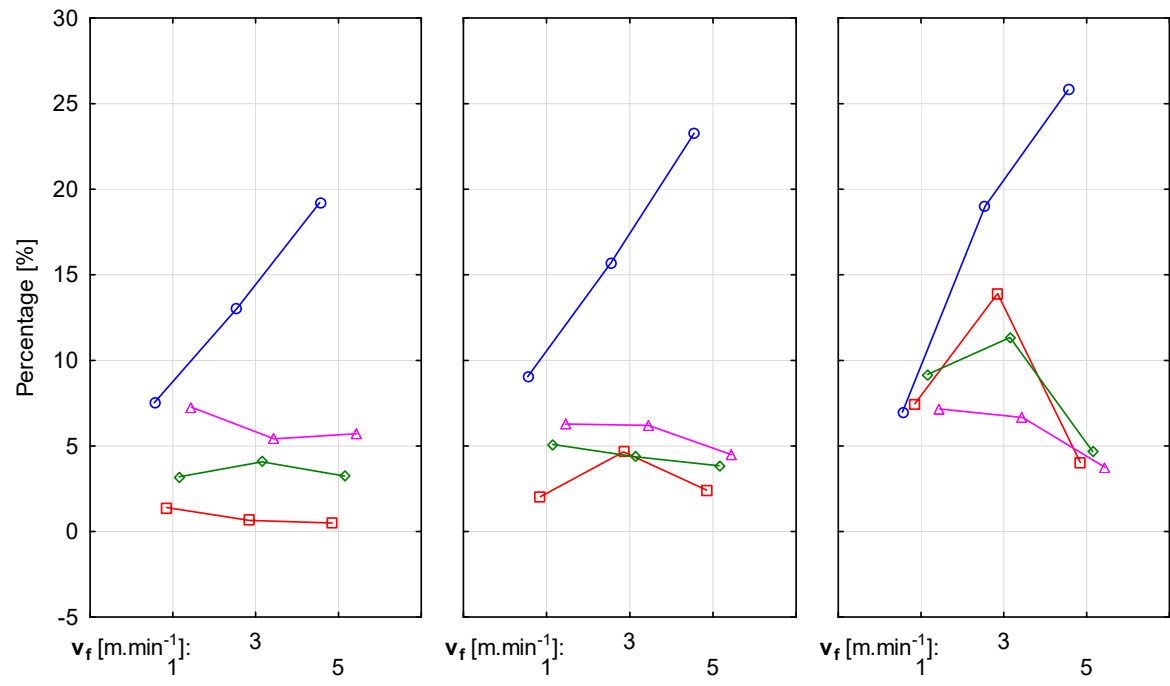

$$
\begin{aligned}
& \text { Depth of cut } \mathbf{e} \text { [mm]: } 1 \\
& \text { Depth of cut } \mathbf{e}[\mathrm{mm}]: 3
\end{aligned}
$$

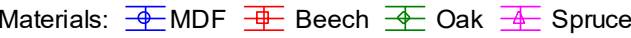

$$
\begin{aligned}
& { }^{*} \mathrm{v}_{\mathrm{f}} \text { - feed speed }\left[\mathrm{m} \cdot \mathrm{min}^{-1}\right]
\end{aligned}
$$

Figure 6. Grain size grade $125 \mu \mathrm{m}$. 


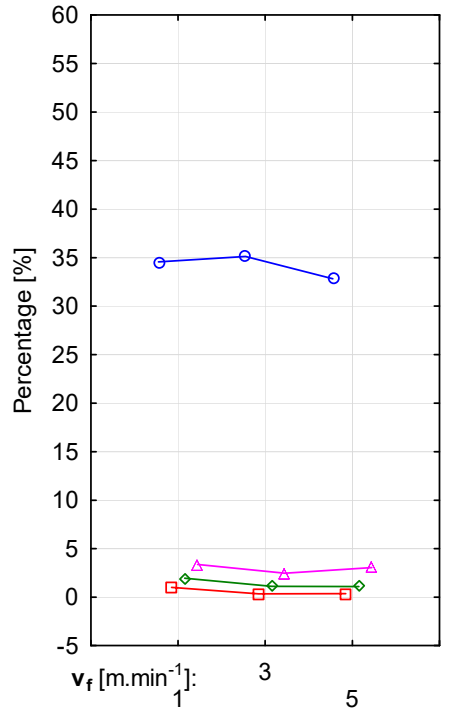

Depth of cut $\mathbf{e}[\mathrm{mm}]$ : 1

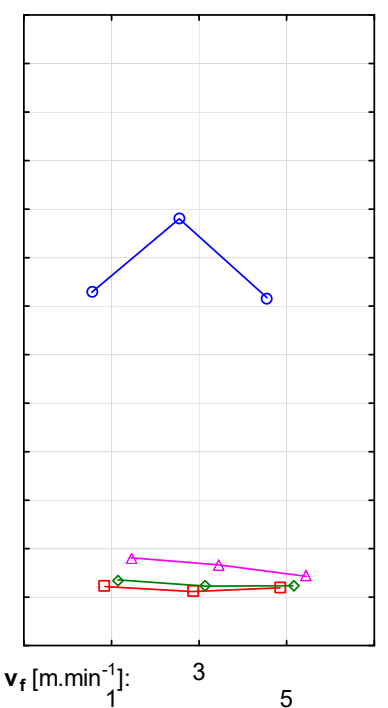

Depth of cut $\mathbf{e}[\mathrm{mm}]: 3$



Depth of cut $\mathbf{e}[\mathrm{mm}]: 5$ ${ }^{*} V_{f}$ - feed speed $\left[\mathrm{m} \cdot \mathrm{min}^{-1}\right.$ ]

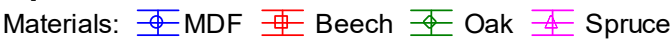

Figure 7. Grain size grade $63 \mu \mathrm{m}$.

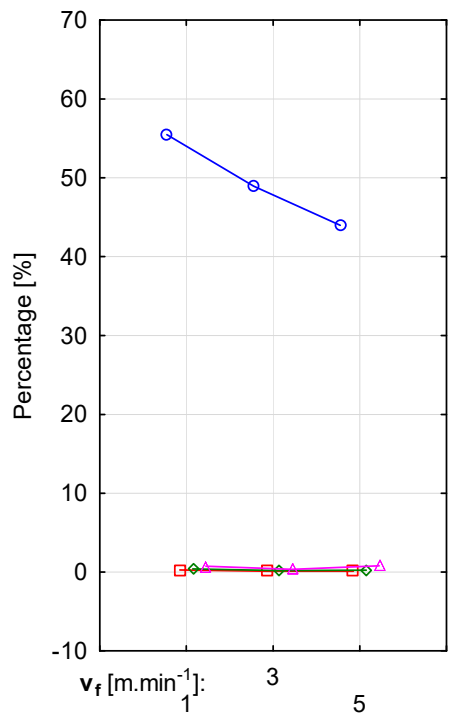

Depth of cut $\mathbf{e}[\mathrm{mm}]: 1$

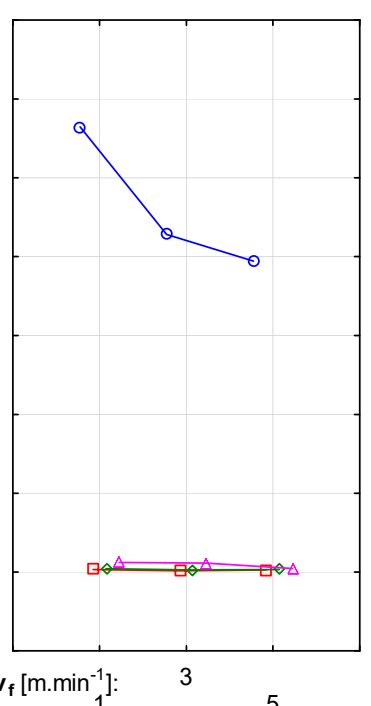

Depth of cut e [mm]: 3

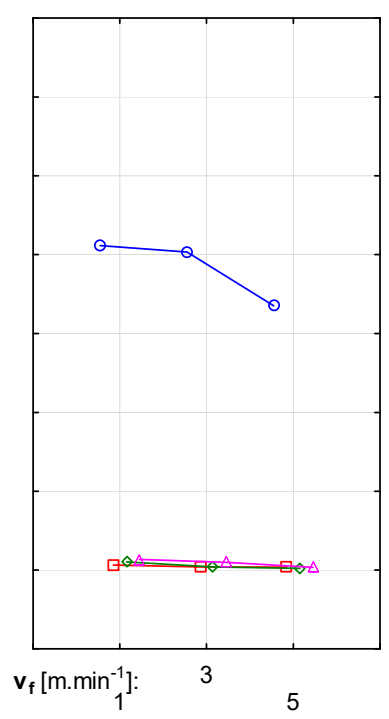

Depth of cut e [mm]: 5 ${ }^{*} \mathrm{v}_{\mathrm{f}}$ - feed speed $\left[\mathrm{m} \cdot \mathrm{min}^{-1}\right]$

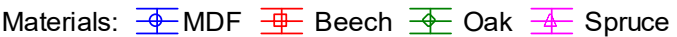

Figure 8. Grain size grade $32 \mu \mathrm{m}$. 


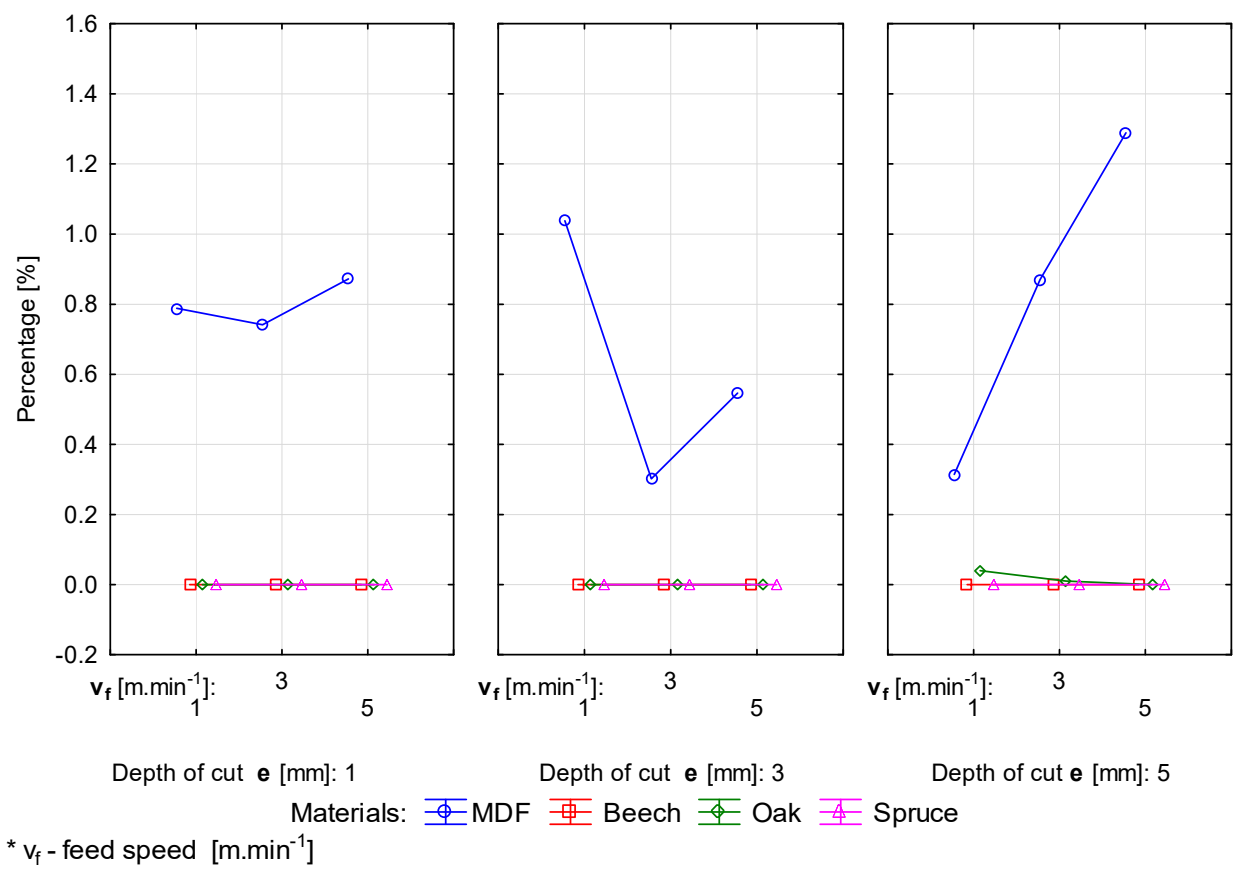

Figure 9. Grain size grade bottom.

The particle size distribution in the case of CNC machining of MDF panels was the opposite. The percentage of the coarse fraction was only $0.27 \% \div 0.51 \%$, and the medium-coarse fractions represented only $1.14 \% \div 9.61 \%$. This means that we can classify the prevailing part of the particles among the fine dust fractions, ranging from $90.1 \%$ to $98.72 \%$. Particle fraction $63 \div 32 \mu \mathrm{m}$ was the predominant grain size grade, ranging from $33.5 \% \div 56.44 \%$. The presence of dust particles below $32 \mu \mathrm{m}$ was also confirmed, which represented $0.3 \% \div 1.29 \%$. The same results were obtained by [43] for four-side molder of MDF. This proves that their content is actually large in this dust [60]. We anticipated such a development based on previously reported results with other MDF machining technologies, but not to such a large extent $[4,13,61-63]$. This can be attributed to the fibrous structure of the material. The fibers are primarily oriented within their thickness in the particle formation process, and the force ratios in the cutting zone cause the material to disintegrate into fine particles (dust) or fiber clumps.

Markedly, the proportion of fraction trapped on the $125 \mu \mathrm{m}$ sieve increased in the case of MDF with increasing depth of cut and the increasing feed rate as well. Conversely, the proportion of this fraction decreased with finer particles trapped on the $32 \mu \mathrm{m}$ sieve with greater depth of cut. The decrease of finer fractions with larger depth of cut was also confirmed by [12]. Other authors $[14,30]$ published in their papers that the proportion of these fractions also increases with increasing feed rate during the machining of particleboard and particles below $125 \mu \mathrm{m}$. However, the particleboard has a different structure that may not correspond to the MDF.

It is possible to identify the effect of shear force on the proportion of smaller particles within the fine fractions in terms of the influence of physical and chemical properties of sawn and sanded material, as well as shape, dimensions, sharpness of cutting tools, and technological factors. The feed rate reduction means the decrease of the nominal thickness of the particle and, thus, the particles move between finer fractions. This fact was also confirmed in the works $[59,64]$. The formation of dust particles can be from all open places of machines as well, especially on the premises of CNC machines as a result of maintenance, repairs, cleaning, inspection, tool change, etc. [42,65-68].

It must be stated in the context of the presented results that the grain size composition of the particles from the milling process is comparable to the grain size composition of the 
particles from the sanding process, and therefore, the same procedures must be chosen when processing such wood material [69-71].

At the same time, the material mix, which will also include particles from the MDF milling process, will cause considerable complications in the subsequent processing of this material, e.g., in the production of briquettes. It is important to point out that the proportion of fine particles will be not negligible.

The paper is based on standard scientific methodologies for the evaluation of particles from the wood milling process, accepted by scientific capacities, but at the same time, we consider it necessary to mention from the point of view of objectivity and in the context of the stated finding

The sieve analysis method alone cannot be used to determine the content of the finest dust particles. They may not pass through very fine sieves due to the complicated shape of the particles, thus, resulting in possible incomplete data analysis. Therefore, complementary analysis methods should be used for wood dust with a larger dimensional span. Only then is it possible to detect and quantify the content of the finest dust particles and, thus, to estimate the occupational health risks accordingly $[30,31]$.

\section{Conclusions}

This research demonstrated that a significant percentage of small dust particles with a size below $100 \mu \mathrm{m}$ is created when machining furniture blanks on CNC machining centers. The comparison of the particle size distributions of wood dust generated during machining of natural wood (beech, oak, and spruce) and MDF panels by a 5-axis CNC machine showed that:

The finest dust fraction was generated during milling of MDF panels, producing particles with predominant grain size ranging from $63 \mu \mathrm{m}$ to $32 \mu \mathrm{m}$. In the case of natural wood, the weight rate of the fine particles was significantly lower than in MDF. The highest content of fine dust particles (below $125 \mu \mathrm{m}$ ) was determined for oak $(5.86 \%)$, followed by spruce $(5.5 \%)$, and beech $(4.06 \%)$, respectively. No clear influence of the feed rate on the fine dust creation was determined. The increased depth of cut resulted in decreased fraction of dust particles with the smallest size.

The formation of fine wood dust particles represents a significant occupational hazard to the health and safety of workers. The results obtained can be used for optimizing the technological programs of CNC milling machines, thus, reducing the occupational exposure to harmful wood dust emissions in the wood-processing industry. High possible depth of cut values should be used to avoid the occupational hazard to the health of woodworkers associated with dustiness.

The improvement of work environment in wood-processing and furniture enterprises by adopting adequate occupational safety and health practices is desirable not only from the perspective of workers but also contributes substantially to labor productivity by enhancing workers' motivation, increasing competitiveness, and promoting economic growth.

Author Contributions: Conceptualization, R.K. and M.K.; methodology, R.K.; validation, P.A. and R.R.; formal analysis, A.O.; investigation, T.R.; data curation, L.K.; writing-original draft preparation, R.K., T.R. and M.P.; writing-review and editing, L.K., P.A. and M.P.; project administration, R.K. All authors have read and agreed to the published version of the manuscript.

Funding: Funding for statutory R\&D activities as the research task No. 506.227.02.00 of Faculty of Forestry and Wood Technology, Poznań University of Life Sciences.

Acknowledgments: This publication is the result of the following projects implementation: project No. НИС-Б-1145/04.2021 “Development, Properties and Application of Eco-Friendly Wood-Based Composites" carried out at the University of Forestry (Sofia, Bulgaria), and projects by the Slovak Research and Development Agency under contracts No. APVV-18-0378, APVV-19-0269, VEGA 1/0324/21 and KEGA 026UMB-4/2021.

Conflicts of Interest: The authors declare no conflict of interest. 


\section{References}

1. Mohan, M.; Aprajita; Panwar, N.K. Effect of Wood Dust on Respiratory Health Status of Carpenters. J. Clin. Diagn. Res. 2013, 7, 1589-1591. [CrossRef] [PubMed]

2. Hlásková, L.; Rogozinski, T.; Dolny, S.; Kopecký, Z.; Jedinák, M. Content of respirable and inhalable fractions in dust created while sawing beech wood and its modifications. Drewno 2015, 58, 135-146.

3. Hancock, D.G.; Langley, M.E.; Chia, K.L.; Woodman, R.J.; Shanahan, E.M. Wood dust exposure and lung cancer risk: A meta-analysis. Occup. Environ. Med. 2015, 72, 889-898. [CrossRef]

4. Rogozinski, T.; Wilkowski, J.; Gorski, J.; Szymanowski, K.; Podziewski, P.; Czarniak, P. Technical note: Fine Particles Content in Dust Created in CNC Milling of Selected Wood Composites. Wood Fiber Sci. 2017, 49, 461-469.

5. Siew, S.S.; Martinsen, J.I.; Kjaerheim, K.; Sparén, P.; Tryggvadottir, L.; Weiderpass, E.; Pukkala, E. Occupational exposure to wood dust and risk of nasal and nasopharyngeal cancer: A case-control study among men in four nordic countries-With an emphasis on nasal adenocarcinoma. Int. J. Cancer 2017, 141, 2430-2436. [CrossRef] [PubMed]

6. Mračková, E.; Krišt'ák, L'.; Kučerka, M.; Gaff, M.; Gajtanska, M. Creation of wood dust during wood processing: Size analysis, dust separation, and occupational health. BioResources 2016, 11, 209-222. [CrossRef]

7. Matrat, M.; Radoi, L.; Févotte, J.; Guida, F.; Cénée, S.; Cyr, D.; Sanchez, M.; Menvielle, G.; Schmaus, A.; Marrer, E.; et al. Occupational exposure to wood dust and risk of lung cancer: The ICARE study. Occup. Environ. Med. 2019, 76, 901-907. [CrossRef]

8. Molnar, Z.; Fuchs, I.; Tatai, S.; Magoss, E. Stability of planed and precision solid wood surfaces due to wetting. Maderas-Cienc. Tecnol. 2019, 21, 123-132. [CrossRef]

9. Nasir, V.; Cool, J. A review on wood machining: Characterization, optimization, and monitoring of the sawing process. Wood Mater. Sci. Eng. 2020, 15, 1-16. [CrossRef]

10. Pedzik, M.; Bednarz, J.; Kwidzinski, Z.; Rogozinski, T.; Smardzewski, J. The Idea of Mass Customization in the Door Industry Using the Example of the Company Porta KMI Poland. Sustainability 2020, 12, 3788. [CrossRef]

11. Rogoziński, T.; Wilkowski, J.; Górski, J.; Czarniak, P.; Podziewski, P.; Szymanowski, K. Dust Creation in CNC Drilling of Wood Composites. Bioresources 2015, 10, 3657-3665. [CrossRef]

12. Piernik, M.; Rogozinski, T.; Krauss, A.; Pinkowski, G. The influence of the thermal modification of pine (Pinus sylvestris L.) wood on the creation of fine dust particles in plane milling: Fine dust creation in the plane milling of thermally modified pine wood. $J$. Occup. Health 2019, 61, 481-488. [CrossRef]

13. Palmqvist, J.; Gustafsson, S.I. Emission of dust in planning and milling of wood. Holz Als Roh Und Werkst 1999, 57, 164-170. [CrossRef]

14. Hlásková, L.; Rogozinski, T.; Kopecký, Z. Influence of Feed Speed on the Content of Fine Dust during Cutting of Two-SideLaminated Particleboards. Drv. Ind. 2016, 67, 9-15. [CrossRef]

15. Hazir, E.; Koc, K.H. Optimization of wood machining parameters in CNC routers: Taguchi orthogonal array based simulated angling algorithm. Maderas-Cienc. Tecnol. 2019, 21, 493-510. [CrossRef]

16. Dünisch, O.; Bauch, J. Influence of Mineral Elements on Wood Formation of Old Growth Spruce (Picea abies [L.] Karst.). Holzforschung 1994, 48, 5-14. [CrossRef]

17. Adler, A. Accumulation of Elements in Salix and Other Species Used in Vegetation Filters with Focus on Wood Fuel Quality. Doctoral Thesis, Swedish University of Agricultural Sciences, Uppsala, Sweden, 2007.

18. Morakinyo, O.M.; Adebowale, A.S.; Mokgobu, M.I. Health risk of inhalation exposure to sub-10 $\mu \mathrm{m}$ particulate matter and gaseous pollutants in an urban-industrial area in South Africa: An ecological study. BMJ Open 2017, 7, e013941. [CrossRef] [PubMed]

19. Nasir, V.; Cole, J. Characterization, optimization, and acoustic emission monitoring of airborne dust emission during wood sawing. Int. J. Adv. Manuf. Technol. 2020, 109, 2365-2375. [CrossRef]

20. Health and Safety Executive. Medium Density Fiberboard (MDF) Hazard Assessment Document; Newsletter of the Wood-Working National Interest Group, National Agricultural Centre: Stoneleigh, UK, 2000. Available online: http://www.hse.gov.uk/ woodworking/woodnig/woodn16.pdf (accessed on 7 May 2021).

21. Burton, C.; Bradshaw, L.; Agius, R.; Burge, S.; Huggins, V.; Fishwick, D. Medium-density fibreboard and occupational asthma. A case series. Occup. Med. 2011, 61, 357-363. [CrossRef]

22. Bell, H.K.; King, C.M. Allergic contact dermatitis from urea-formaldehyde resin in medium-density fibreboard (MDF). Contact Dermat. 2002, 46, 247. [CrossRef]

23. Jacobsen, G.; Schaumburg, I.; Sigsgaard, T.; Schlünssen, V. Non-malignant respiratory diseases and occupational exposure to wood dust. Part I. Fresh wood and mixed wood industry. Ann. Agric. Environ. Med. 2010, 17, 15-28.

24. Hejna, A.; Marc, M. Towards Understanding the Health Aspects of the Processing of Lignocellulosic Fillers. Proceedings 2020, 69, 34. [CrossRef]

25. IARC. Wood dust. A review of human carcinogens: Arsenic, metals, fibres, and dusts. In IARC Monographs on the Evaluation of Carcinogenic Risks to Humans/World HEALTH Organization; International Agency for Research on Cancer: Lyon, France, 2012; Available online: https:/ / www.iarc.who.int/ (accessed on 7 May 2021). 
26. Directive (EU) 2017/2398 of the European Parliament and of the Council of 12 December 2017 amending Directive 2004/37/EC on the Protection of Workers from the Risks Related to Exposure to Carcinogens or Mutagens at Work. Available online: http:/ / data.europa.eu/eli/dir/2017/2398/oj (accessed on 8 May 2021).

27. Scientific Committee on Occupational Exposure Limits (SCOEL). Recommendation from the Scientific Committee on Occupational Exposure Limits for Wood Dust; SCOEL/SUM/102B: Brussels, Belgium, 2002.

28. Bhatti, P.; Newcomer, L.; Onstad, L.; Teschke, K.; Camp, J.; Morgan, M.; Vaughan, T.L. Wood dust exposure and risk of lung cancer. Occup. Environ. Med. 2011, 68, 599-604. [CrossRef]

29. Pędzik, M.; Stuper-Szablewska, K.; Sydor, M.; Rogoziński, T. Influence of Grit Size and Wood Species on the Granularity of Dust Particles During Sanding. Appl. Sci. 2020, 10, 8165. [CrossRef]

30. Pałubicki, B.; Hlásková, L.; Frömel-Frybort, S.; Rogozinski, T. Feed Force and Sawdust Geometry in Particleboard Sawing. Materials 2021, 14, 945. [CrossRef] [PubMed]

31. Harrell, M.; Selvaraj, S.A.; Edgar, M. DANGER! Crisis Health Workers at Risk. Int. J. Environ. Res. Public Health 2020, 17, 5270. [CrossRef]

32. Tudor, E.M.; Zwickl, C.; Eichinger, C.; Petutschnigg, A.; Barbu, M.C. Performance of softwood bark comminution technologies for determination of targeted particle size in further upcycling applications. J. Clean. Prod. 2020, 269, 122412. [CrossRef]

33. Chung, K.; Cuthbert, R.; Revell, G.; Wassel, S.; Summers, N. A study on dust emission, particle size distribution and formal-dehyde concentration during machining of medium density fibreboard. Ann. Occup. Hyg. 2000, 44, 455-466. [CrossRef]

34. Hejna, A.; Marć, M.; Skorczewska, K.; Szulc, J.; Korol, J.; Formela, K. Insights into modification of lignocellulosic fillers with isophorone diisocyanate: Structure, thermal stability and volatile organic compounds emission assessment. Eur. J. Wood Wood Prod. 2021, 79, 75-90. [CrossRef]

35. Hejna, A.; Marc, M.; Korol, J. Modification of cellulosic filler with diisocynates-Volatile organic compounds emission assessment and stability of chemical structure over time. Nord. Pulp Pap. Res. J. 2021, 36, 353-372. [CrossRef]

36. Taghiyari, H.R.; Esmailpour, A.; Papadopoulos, A.N. Paint Pull-Off Strength and Permeability in Nanosilver-Impregnated and Heat-Treated Beech Wood. Coatings 2019, 9, 723. [CrossRef]

37. Papadopoulos, A.N.; Taghiyari, H.R. Innovative Wood Surface Treatments Based on Nanotechnology. Coatings 2019, 9, 866. [CrossRef]

38. Taghiyari, H.R.; Bayani, S.; Militz, H.; Papadopoulos, A.N. Heat Treatment of Pine Wood: Possible Effect of Impregnation with Silver Nanosuspension. Forests 2020, 11, 466. [CrossRef]

39. Kauppinen, T.; Vincent, R.; Liukkonen, T.; Grzebyk, M.; Kauppinen, A.; Welling, I.; Arezes, P.; Black, N.; Bochmann, F.; Campelo, F.; et al. Occupational Exposure to Inhalable Wood Dust in the Member States of the European Union. Ann. Occup. Hyg. 2006, 50, 549-561. [CrossRef] [PubMed]

40. Dutkiewicz, J.; Cisak, E.; Sroka, J.; Wójcik-Fatla, A.; Zając, V. Biological agents as occupational hazards—Selected issues. Ann. Agric. Environ. Med. 2011, 18, 286-293.

41. Sinn, G.; Chuchala, D.; Orlowski, K.A.; Taube, P. Cutting model parameters from frame sawing of natural and impregnated Scots pine (Pinus sylvestris L.). Eur. J. Wood Wood Prod. 2020, 78, 777-784. [CrossRef]

42. Tureková, I.; Mračková, E.; Marková, I. Determination of Waste Industrial Dust Safety Characteristics. Int. J. Environ. Res. Public Health 2019, 16, 2103. [CrossRef] [PubMed]

43. Vandličková, M.; Marková, I.; Makovická Osvaldová, L.; Gašpercová, S.; Svetlík, J.; Vraniak, J. Tropical Wood DustsGranulometry, Morfology and Ignition Temperature. Appl. Sci. 2020, 10, 7608. [CrossRef]

44. Očkajová, A.; Kučerka, M.; Kminiak, R.; Krišt'ák, L'.; Igaz, R.; Réh, R. Occupational Exposure to Dust produced when Milling Thermally Modified Wood. Int. J. Environ. Res. Public Health 2020, 17, 1478. [CrossRef] [PubMed]

45. Vandličkova, M.; Markova, I.; Holla, K.; Gašpercová, S. Evaluation of Marblewood Dust's (Marmaroxylon racemosum) Effect on Ignition Risk. Appl. Sci. 2021, 11, 6874. [CrossRef]

46. Andersen, A.; Barlow, L.; Engeland, A.; Kjaerheim, K.; Lynge, E.; Pukkala, E. Work-related cancer in the Nordic countries. Scand. J. Work. Environ. Health 1999, 25, 1-114. [PubMed]

47. Yu, M.C.; Yuan, J.-M. Epidemiology of nasopharyngeal carcinoma. Semin. Cancer Biol. 2002, 12, 421-429. [CrossRef] [PubMed]

48. Orlowski, K.; Chuchala, D.; Muzinski, T.; Baranski, J.; Banski, A.; Rogozinski, T. The effect of wood drying method on the granularity of sawdust obtained during the sawing process using the frame sawing machine. Acta Fac. Xylologiae Zvolen 2019, 61, 83-92.

49. Hill, C.; Norton, A.; Dibdiaková, J. A comparison of the environmental impacts of different categories of insulation materials. Energy Build. 2018, 162, 12-20. [CrossRef]

50. EN 324-1. Wood-Based Panels_Determination of Thickness, Width and Length; European Committee for Standardization: Brussels, Belgium, 1993.

51. EN 324-2. Wood-Based Panels—Determination of Squareness and Edge Straightness; European Committee for Standardization: Brussels, Belgium, 1993.

52. EN 322. Wood-Based Panels-Determination of Moisture Content; European Committee for Standardization: Brussels, Belgium, 1998.

53. EN ISO 12460-5. Wood-Based Panels-Determination of Formaldehyde Release-Part 5. Extraction Method (Called the Perforator Method); European Committee for Standardization: Brussels, Belgium, 2015. 
54. EN 310. Wood-Based Panels-Determination of Modulus of Elasticity in Bending and of Bending Strength; European Committee for Standardization: Brussels, Belgium, 1999.

55. EN 319. Particleboards and Fibreboards-Determination of Tensile Strength Perpendicular to the Plane of the Board; European Committee for Standardization: Brussels, Belgium, 1993.

56. EN 317. Particleboards and Fibreboards-Determination of Swelling in Thickness after Immersion in Water; European Committee for Standardization: Brussels, Belgium, 1998.

57. ISO 9096:2017. Air quality. Stationary Source emissions. Manual Determination of Mass concentration of Particulate Matter; International Organization for Standardization: Geneva, Switzerland, 2017.

58. ISO 3310-1:2016. Test Sieves—Technical Requirements and Testing_Part 1: Test Sieves of Metal Wire Cloth; International Organization for Standardization: Geneva, Switzerland, 2016.

59. Kminiak, R.; Banski, A. Granulometric analysis of chips from beech, oak and spruce woodturning blanks produced in the milling process using axial CNC machining center. Acta Fac. Xylologiae 2019, 61, 75-82.

60. Svoreň, J.; Naščák, L'.; Koleda, P.; Barcík, Š.; Němec, M. The circular saw blade body modification by elastic material layer effecting circular saws sound pressure level when idling and cutting. Appl. Acoust. 2021, 179, 108028. [CrossRef]

61. Atanasov, V.; Kovatchev, G. Determination of the cutting power during milling of wood-based materials. Acta Fac. Xylologiae 2019, 61, 93-101.

62. Orlowski, K.A.; Dudek, P.; Chuchala, D.; Blacharski, W.; Przybylinski, T. The Design Development of the Sliding Table Saw Towards Improving its Dynamic Properties. Appl. Sci. 2020, 10, 7386. [CrossRef]

63. Valcheva, L.; Savov, V. The Effect of Thickness of Medium Density Fiberboard Produced of Hardwood Tree Species on their Selected Physical and Mechanical Properties. Key Eng. Mater. 2016, 688, 115-121. [CrossRef]

64. Kminiak, R.; Dzurenda, L. Impact of Sycamore Maple Thermal Treatment on a Granulometric Composition of Chips Obtained due to Processing on a CNC Machining Centre. Sustainability 2019, 11, 718. [CrossRef]

65. Dzurenda, L.; Wasielewski, R.; Orlowski, K. Granulometric analysis of dry saw-dust from sawing process on the frame sawing Machine PRW-15M. Acta Fac. Xylologiae 2006, 48, 51-57.

66. Igaz, R.; Kminiak, R.; Krišt'ák, L.; Němec, M.; Gergel', T. Methodology of Temperature Monitoring in the Process of CNC Machining of Solid Wood. Sustainability 2019, 11, 95. [CrossRef]

67. Kopecký, Z.; Rousek, M. Dustiness in high-speed milling. Wood Res. 2007, 52, 65-76.

68. Goli, G.; Fioravanti, M.; Marchal, R.; Uzielli, L. Up-milling and down-milling wood with different grain orientations-Theoretical background and general appearance of the chips. Eur. J. Wood Prod. 2009, 67, 257-263. [CrossRef]

69. Taube, P.; Orlowski, K.A.; Chuchala, D.; Sandak, J. The Effect of Log Sorting Strategy on the Forecasted Lumber Value After Sawing Pine Wood. Acta Fac. Xylologiae 2020, 62, 89-102.

70. Očkajová, A.; Kučerka, M.; Krišt'ák, L'.; Igaz, R. Granulometric Analysis of Sanding Dust from Selected Wood Species. Bioresources 2018, 13, 7481-7495. [CrossRef]

71. Licow, R.; Chuchala, D.; Deja, M.; Orlowski, K.A.; Taube, P. Effect of Pine Impregnation and Feed Speed on Sound Level and Cutting Power in Wood Sawing. J. Clean. Prod. 2020, 272, 122833. [CrossRef] 